REVISTA CIENTÍFICA RURAL

ISSN: 1413-8263 2525-6912
Revista Técnico-Científica
๙ิ

urcomp

\title{
INFLUÊNCIA DA VELOCIDADE DE SEMEADURA NO ESTABELECIMENTO E PRODUTIVIDADE DO MILHO
}

${ }^{1}$ Carlos Henrique dos Santos Fernandes, ${ }^{1}$ Débora Perdigão Tejo, ${ }^{2} \mathrm{Klever}$ Márcio Antunes Arruda

${ }^{1}$ Universidade Norte do Paraná - Graduação em Agronomia, (carloshenrique_fernandes_@hotmail.com; deboratejo@hotmail.com). ${ }^{2}$ Eng. Agr. Pesquisador, Instituto Agronômico do Paraná, Londrina, Pr, (klever@iapar.br).

RESUMO: A cadeia produtiva do milho (Zeamays L.) é um dos segmentos econômicos chave do agronegócio brasileiro, entretanto mesmo com os ganhos de produção, a produtividade média alcançada na cultura ainda está muito abaixo do potencial produtivo. Todavia, a utilização de ferramentas que possam aumentar a produtividade é fundamental para a sustentabilidade da atividade. O rendimento de grãos depende de vários fatores, entretanto o potencial produtivo é parte definido no momento da semeadura. Para se alcançar qualidade de semeadura os implementos, assim como sua forma de utilização, são fatores que irão influenciar nos resultados obtidos, sendo mais evidente na cultura do milho em detrimento de sua baixa plasticidade. O objetivo deste trabalho foi apresentar os fatores relacionados à plantabilidade do milho, com foco na influência da velocidade de deslocamento de uma semeadora no estabelecimento e produtividade do milho. Pode se concluir que à medida que se aumenta a percentagem de espaçamentos falhos e múltiplos e queda de espaçamentos aceitáveis ao se elevar a velocidade de deslocamento da semeadoraadubadora, reduz drasticamente a uniformidade de plantio e consequentemente 0 rendimento de grãos.

Palavras-chave: Plantabilidade; Semeadura; Deslocamento; Densidade de plantas.

\section{INFLUENCE OF SOWING SPEED ON CORN ESTABLISHMENT AND PRODUCTIVITY}

ABSTRACT: The maize (Zea mays L.) production chain is one of the important economic segments of Brazilian agribusiness, but even with the gains of production, the average productivity reached in the crop is still far below the productive potential. However, the use of tools that can increase productivity is fundamental to the sustainability of the activity. The yield of grains depends on several factors, however the productive potential is a defined part at the time of sowing. In order to achieve seed quality, the implements, as well as their way of use, are factors that will influence the results obtained, being more evident in the maize crop to the detriment of its low plasticity. The objective of this work was to present the factors related to maize plantability, focusing on the influence of the speed of movement of a seed in the establishment and yield of maize. It can be concluded that with the increase of sowing 
speed, a greater percentage of faults or double plants occurs, reducing the uniformity of planting and consequently grain yield.

Keywords: Plantability; Seeding; Displacement; Density of plants.

INTRODUÇÃO

O milho (Zeamays L.) é amplamente cultivado mundialmente desde seu processo de domesticação, onde foi alimento básico de muitas sociedades préhistóricas (PIPERNO; FLANNERY, 2001). O centro de origem ocorreu na região mesoamericana e propõe-se que a domesticação do Zea selvagem tenha ocorrido no México, segundo alguns investigadores em cerca de 10.000 a 7.000 anos 14 C B.P. e outros sugerem que ocorreu em cerca de 6.000 - 5.000 14C anos B.P. (YABUNO, 1971; GALINAT,1962).

O cenário agrícola nas últimas décadas sofreu grandes avanços relacionados a pesquisas cientificas e a alta difusão tecnológica (FORSTHOFER et al., 2006). milho (Zeamays L.) é umas das culturas que possui alto emprego tecnológico e destaca-se no mercado mundial de produção de grãos em detrimento de sua elevada importância nutricional e econômica, que se dá em função da sua ampla destinação de uso que vai da alimentação humana e animal até a fabricação de diversos subprodutos da cadeia industrial, sendo então cultivado em quase todos os continentes e atualmente a produção brasileira ocupa a terceira posição, logo atrás dos Estados Unidos e China (BACCHI; CALDARELLI; SEREIA, 2017).

Para obter um rendimento de grãos satisfatório, depende-se de vários fatores, entretanto o potencial produtivo é definido no momento da semeadura, sendo indispensável que haja uma boa plantabilidade do milho (BONDESIO; KLOPPERS; OELLERMANN, 2016). O tipo e estado do solo, assim como dos insumos e implementos vão interferir na qualidade da semeadura: Os implementos interferem em decorrência do tipo de sulcador, da pressão do pneu da roda motriz, do tubo condutor das sementes, do estado de conservação da máquina, do sistema dosador de sementes e adubo, assim como da velocidade de semeadura (CELIK; OZTURK; WAY, 2007).

A cultura do milho possui baixa plasticidade não se adaptando facilmente a diferentes arranjos espaciais, com isso quando ocorrem falhas e/ou plantas duplas podem interferir na produção devido ao pouco ou ausente efeito compensatório do 
milho (ARGENTA; SILVA; SANGOI, 2001). O mesmo autor cita que o estabelecimento de um estande de plantas ideal, a distribuição de sementes, assim como o rendimento de grãos pode ser influenciado por diversos fatores. Diante disso, este trabalho tem como problema de pesquisa central responder a seguinte questão: Quais são os fatores que influenciam na produtividade de milho relacionados à plantabilidade da cultura?

Portanto, o objetivo do presente trabalho, é apresentar a influência da velocidade de deslocamento de uma semeadora no estabelecimento e produtividade do milho. Os objetivos específicos são: caracterizar é identificar fatores que interferem no rendimento de grãos; verificar os fatores relacionados à plantabilidade do milho; e a influência da velocidade de semeadura.

\section{MATERIAL E MÉTODOS}

O presente trabalho trata-se de uma revisão de literatura, elaborado em cima de consultas em livros e artigos publicados em revistas com teor científico. Os materiais foram buscados nas bases de dados Google Acadêmico e Scielo, sendo utilizadas as palavras chaves: Milho; Plantabilidade; Semeadura; Deslocamento; Densidade de plantas.

\section{FATORES QUE INTEREFEREM NO RENDIMENTO DE GRÃOS}

O cultivo de milho no Brasil se dá em duas safras distintas, sendo a primeira e principal na primavera-verão e a segunda no outono-inverno, sendo esta conhecida por "safrinha" devido a menor janela de produção em decorrência das condições climáticas e a sucessão com a soja, entretanto seu cultivo vem ganhando importância e ultrapassando a produtividade média da primeira safra em algumas regiões do país (ARAÚJO, 2008).

Estudos realizados avaliando os avanços na produção do milho no período de 1940 a 1990 nos EUA evidenciaram que a cultura em função do melhoramento genético atrelado aos demais fatores impactantes, foi uma das que mais apresentou incrementos elevados de rendimento de grãos (RUSSEL, 1991).

Em decorrência do melhoramento genético, há materiais com boa adaptabilidade aos mais diversos tipo de solo, clima e altitudes, é possível que haja o cultivo da espécie desde o nível do mar até $3.600 \mathrm{~m}$ de altitude e desde que haja 
disponibilidade hídrica ao longo do ciclo e tenha temperatura média diurna superior a $19^{\circ} \mathrm{C}$ e noturna acima de $12,8^{\circ} \mathrm{C}$ para atingir um alto desempenho produtivo (DARÓS, 2008), consequentemente um alto rendimento de grãos.

Sabe-se que o clima é um dos fatores determinantes para obter bons rendimentos de grãos, pois em períodos de déficit hídrico, assim como chuvas torrenciais associadas a ventos fortes, incidência de radiação deficitária, temperaturas extremas e alto nível gás carbônico $\left(\mathrm{CO}_{2}\right)$ vai ser prejudicial ao desenvolvimento das plantas e também vai ter influência na população de insetos e micro-organismos (HATFIELD et al., 2011).

Tudo é reflexo de um complexo conjunto de fatores, por exemplo, a água é determinante para as características fisiológicas e morfológicas da cultura, como seu uso na transpiração, com isso estudo de meta analise conduzido por Wand et al., (1999) mostrou que plantas em ambientes com elevadas taxas de cO2 reduzem a condutância estomacal em 39\% na C3 e 29\% nas espécies de plantas C4, que é o caso do milho.

A cultura do milho é bastante responsiva a adoção de tecnologias, além da escolha do material genético, as mudanças nas práticas culturais têm sido responsáveis por uma parcela significativa dos ganhos de rendimento, sendo então estas subutilizadas ou mal-empregadas tornam-se entraves de produção (MAGALHÃES et al., 2002). As práticas de manejo de culturas como o controle de plantas daninha, pragas, doenças, momento de aplicação dos insumos, manejo de solo, monitoramento, oportunidade do plantio e o aumento da eficiência dos implementos agrícolas, dentre outros, são então intrínsecas para alcançar altos rendimentos (FANCELLI; ALVES; ALMEIDA, 2015).

Dentre as práticas de manejo, a qualidade da semeadura é decisiva para o estabelecimento de uma cultura, pois está refletirá na população e distribuição espacial adequada das plantas (arranjo), e consequentemente, havendo assertividade na implantação da cultura influenciará na produtividade (SCHMIDT et al., 1999). A plantabilidade por sua vez, é afetada por diversas variáveis, entretanto a velocidade de deslocamento na semeadura do milho há posição de destaque (GARCIA et al, 2006a). 
Os limites de produtividade são importantes e bastante explorados nos programas de melhoramento genético, entretanto um alto rendimento de grão será consequência da junção de diversos fatores citados, dentre eles, destaca-se o papel da interceptação da radiação fotossinteticamente ativa pelas plantas, pois esta exerce elevada influência sobre o desempenho do material quando outros fatores ambientais são favoráveis, assim como depende de uma boa plantabilidade para ter seu desempenho melhor aproveitado (OTTMAN; WELCH, 1989). Entretanto no campo a eficiência do uso da radiação solar pelas plantas geralmente é muito baixa, com isso a obtenção de um arranjo de plantas adequado pode favorecer uma melhor interceptação da radiação, na eficiência de sua utilização, que consequentemente irá refletir no rendimento de grãos das culturas conforme ilustra fluxograma abaixo (Figura 1) (ARGENTA; SILVA; SANGOI, 2001).

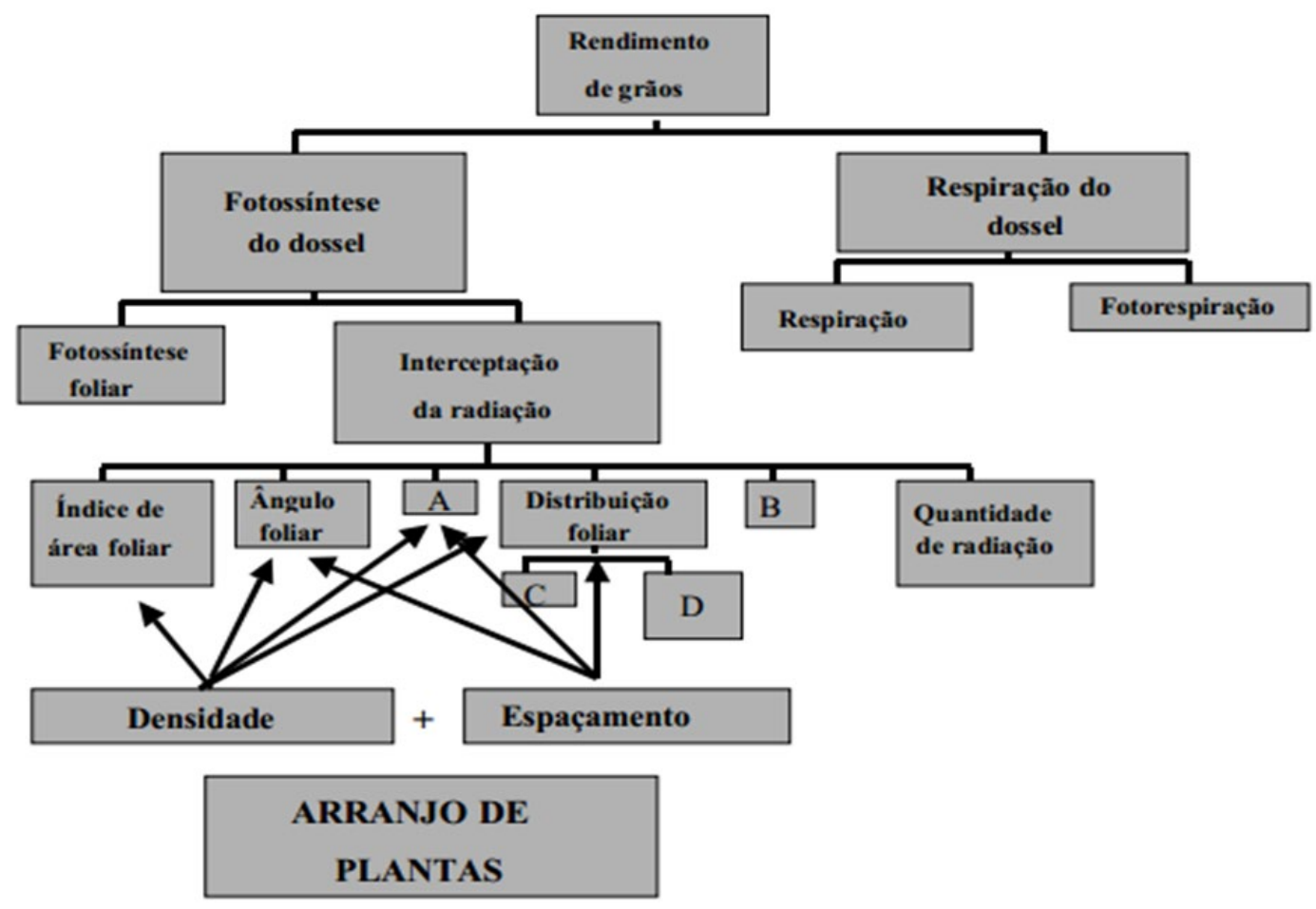

Figura 1. Fluxograma dos fatores que interferem o rendimento de grão. Fonte:Argenta; Silva; Sangoi, 2001.

Figure 1.Flowchart of factors that affect grain yield. Source: Argenta; Silva; Sangoi, 2001.

A Plantabilidade como já visto, implica na "distribuição das sementes em plantios de milho de alta densidade, tanto em profundidade quanto em relação à distância entre as plantas nas fileiras e entre linhas e a velocidade do plantio", sendo determinante no estabelecimento da cultura (MANTOVANI; CRUZ. OLIVEIRA, 2013). 
Tais fatores pontuados são considerados imprescindíveis ao aumento na produtividade do milho.

\section{QUALIDADE DE SEMEADURA}

O potencial de rendimento de uma lavoura é definido no momento da semeadura, que vai desde a escolha de uma cultivar adequada para região, épocas de semeadura, condições climáticas, níveis de manejo aplicado, ao arranjo de plantas, ao nível de adubação química e ao controle fitossanitário realizado (FORSTHOFER et al., 2006). Sendo assim, sabendo-se que o solo, os insumos e máquinas são fatores que interferem na qualidade da semeadura, há diversas pesquisas direcionadas a esses fatores a fim de possibilitar uma semeadura correta, que consequentemente favorecerá a cultura expressar seu potencial genético

O planejamento de semeadura é importante porque dependendo da forma e momento pode influenciar nos demais estádios fenológicos da cultura, pois o desenvolvimento é um processo contínuo e interligado, em que cada fase possui um papel crucial que reflete no rendimento final (BORÉM; GALVÃO; PIMENTEL, 2015).Para melhor visualizar os possíveis efeitos ao longo do ciclo da cultura do milho, é necessário compreender a importância de cada estágio de desenvolvimento da cultura, que são divididos entre a fase vegetativa $(V)$ e reprodutiva $(R)$, sendo definido cada um quando, pelo menos $50 \%$ das plantas estiverem no mesmo estádio: Os estádios vegetativos (V) são definidos quando a planta apresenta a última folha expandida fora do cartucho, e é classificado de $\mathrm{V} 0$ até $\mathrm{Vn}$, onde $\mathrm{n}$ representa o último estádio vegetativo anterior ao pendoamento. Já estádios reprodutivos começam após o pendoamento e vão até a maturação dos grãos (BONHOMME; KINIRY, 1990) (Figura 2). 


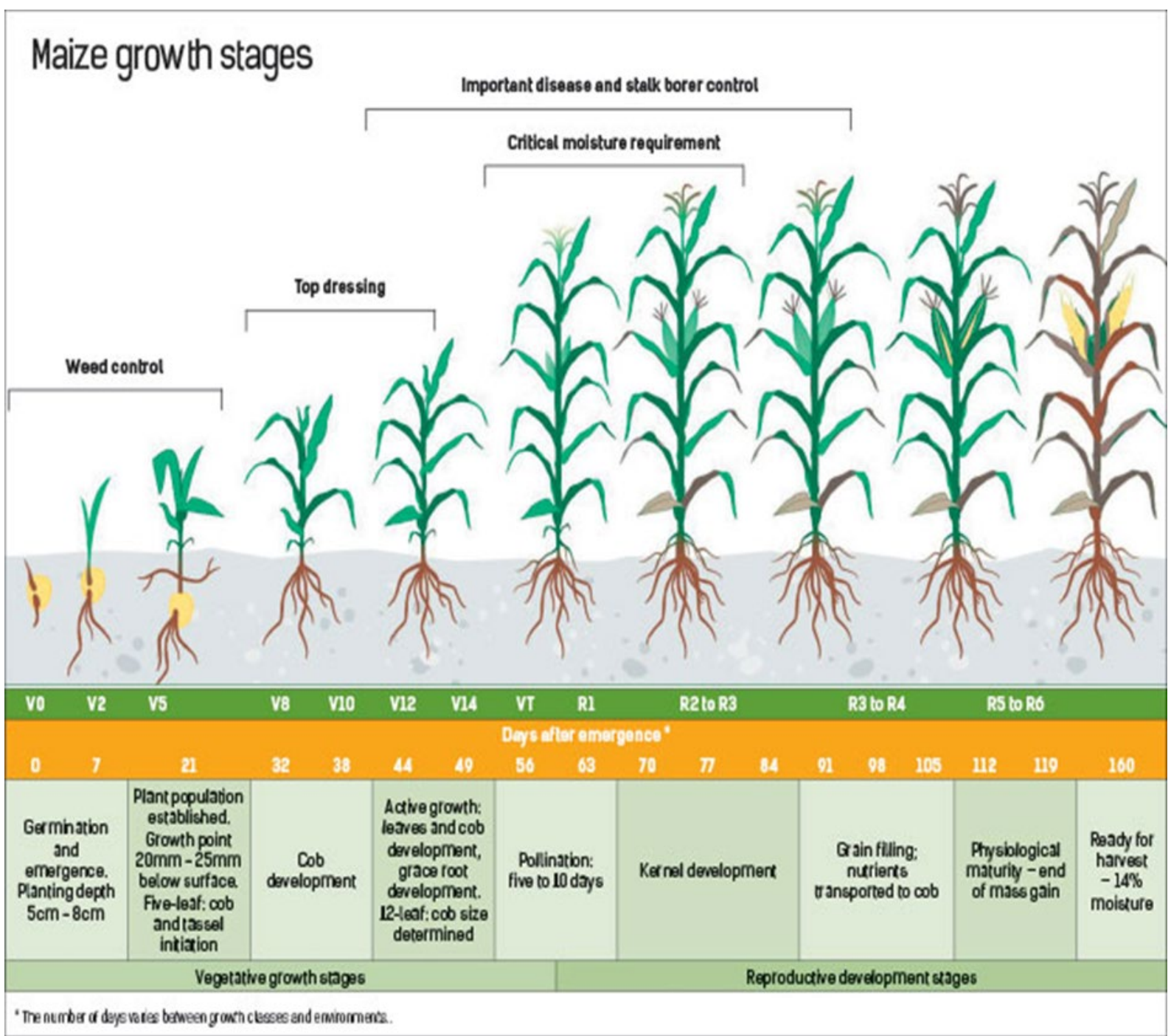

Figura 2. Estádio fenológicos do milho e fatores que podem afetar o desenvolvimento da cultura. Fonte:Bondesio; Kloppers; Oellermann, 2016 - PANNAR.

Figure 2. Phenological stage of maize and factors that may affect crop development. Source:Bondesio; Kloppers; Oellermann, 2016 - PANNAR.

Como visto anteriormente diversos fatores podem interferir na qualidade de semeadura e uma vez esta não realizada corretamente vai influenciar em diferentes etapas do desenvolvimento da cultura. Os fatores que podem interferir na qualidade de semeadura são: solo, insumos e máquinas. Com base no solo o tipo de preparo realizado vai variar caso seja um plantio convencional ou direto, assim como a presença de torrões, compactação e a umidade do solo; Já os insumos irão influenciar com relação à quantidade de sementes e adubo aplicados, a qualidade do fertilizante, assim como o tamanho e uniformidade das sementes; As semeadoras por sua vez, os resultados vão variar conforme o estado de conservação da máquina, o tipo de 
sulcador utilizado, tubo condutor das sementes, a pressão do pneu da roda motriz, o sistema dosador de sementes e adubo, assim como a velocidade de deslocamento da semeadora (LAURIANO, 2015).

A qualidade de semeadura com base no desempenho das máquinas empregadas na operação é fundamental que haja a adequação da configuração, sendo uma correta regulagem das semeadoras-adubadoras, de modo que, sempre se leve em consideração o tipo desolo presente na área, assim como a situação do terreno e não menos importante a da cobertura vegetal pré-existente em caso de semeadura direta (SILVA, 2007).

A semeadura adequada pode ser definida quando ocorre com um espaçamento uniforme, ótima porcentagem de germinação das sementes e que o tempo necessário para emergência de toda a população de plântulas seja o menor possível (MARONI et al., 2005), ou seja, espera se que se tenha qualidade de semeadura, sendo esta obtida da soma de diversos fatores como a utilização de sementes de qualidade, bom desempenho do implemento em abrir o sulco de semeadura, distribuir na profundidade correta, assim como na posição da linha e entre linha respeitando o espaçamento adequado, e após estar no local adequado que as sementes sejam recobertas de modo a ficar em contato com o solo e a água(MÁRQUEZ, 2004).

\section{ÉPOCA DE SEMEADURA}

Como qualquer outra planta, o período de crescimento e de desenvolvimento do milho é influenciado pelas condições climáticas, ocorrendo então limitações conforme a época de semeadura (VON PINHO et al., 2007), sendo importante respeitar o zoneamento agrícola de cada região.

No período que for realizar a semeadura, para se ter um bom aproveitamento da operação, é interessante que seja verificado a condição de umidade do solo. Conforme Viera; Reis (2001), a maioria das semeadoras possui mecanismos dosadores de sementes/adubos acionados pelo rodado, sendo esse influenciado diretamente pela situação que ocorre o seu contato com o solo, seja pelas características da roda, da carga vertical ou das propriedades físicas do solo, de modo que, essas variáveis determinam o índice de deslizamento do rodado.

Em áreas onde é realizada semeadura direta geralmente ocorre menor índice de deslizamento do rodado, pois a cobertura presente confere melhor resistência do 
solo ao rolamento, tornando possível realizar a semeadura em épocas com maior teor de água no solo, diferente de uma área com preparo convencional que se torna inviável a operação (VIEIRA; REIS, 2001).

\section{DISTRIBUIÇÃO DE SEMENTES}

A não uniformidade do espaçamento entre sementes está geralmente relacionada ao método de distribuição de sementes ao sulco e à velocidade de deslocamento do plantio (FORNSTROM; MILLER, 1989).

De acordo com a Associação Brasileira de Normas Técnicas - ABNT (1994), as semeadoras são classificadas, conforme a forma de distribuição de sementes, em semeadoras de "fluxo contínuo" e "de precisão", respectivamente sendo utilizadas para sementes miúdas (trigo) e graúdas (milho).

Sendo que a de fluxo contínuo a dose de sementes é calculada pela razão entre a massa e distância percorrida $(\mathrm{kg} / \mathrm{m}$ ou $\mathrm{g} / \mathrm{m})$ e a distribuição ocorre de forma contínua no sulco, enquanto uma semeadora de precisão a distribuição ocorre comum número pré-determinado de sementes a cada metro de sulco. Também se encontra máquinas denominadas de Multissemeadoras que possuem mecanismos passíveis a mudanças e/ou adaptações, de modo que, torna possível executar a semeadura em ambas as formas de distribuição e semear diversas sementes viabilizando o uso do mesmo implemento para culturas de inverno e verão (TOLEDO, 2015).

Segundo Kachman; Smith (1995), estudando medidas alternativas de precisão no espaçamento de plantas para semeadoras usando a dosagem de sementes individuais, verificou que o espaçamento médio e o desvio padrão do espaçamento entre sementes são úteis, mas não caracterizam completamente a distribuição do espaçamento entre plantas para semeadoras de sementes individuais. Segundo esses autores, o índice múltiplo, o índice de falhas, a qualidade do índice de alimentação e a precisão devem ser consideradas além da média e do desvio padrão do espaçamento de sementes, porque a distância entre plantas dentro de uma linha é influenciada por vários fatores, incluindo sementes múltiplas que caem ao mesmo tempo, a falta de uma semente a ser derrubada, a falta de sementes e a variabilidade em torno do ponto de queda. 


\section{DENSIDADE DE SEMEADURA}

A densidade de semeadura é a quantidade de plantas por área, também denominada de estante, onde pequenas variações influenciam na produtividade brasileira de milho, isto ocorre porque o milho é a gramínea mais sensível à variação populacional, com isso para cada sistema de produção, existe uma população que maximiza o rendimento de grãos (CRUZ et al., 2010).

O milho é uma cultura que possui baixa plasticidade, com isso se torna necessário que haja uma boa população de plantas, que estas estejam distribuídas uniformemente e não possuam danos mecânicos causados pelos mecanismos dos dosadores (MANTOVANI, 2003).

Segundo Sangoi (2000), a densidade ideal para potencializar o rendimento de grãos de milho varia de 30.000 a 90.000 plantas ha-1, variando conforme o ciclo da cultivar, o espaçamento entre linhas, a época de semeadura, assim como a disponibilidade hídrica e fertilidade do solo. Corroborando com os resultados de Teixeira et al. (2006), onde verificara o efeito da densidade de plantas e do espaçamento entre linhas no desempenho de cultivares de milho e concluíram que a

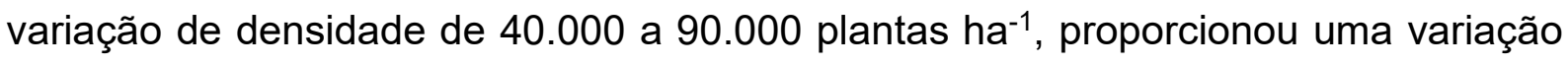
de rendimento de grãos, oscilando conforme o genótipo.

Com base nas cultivares atual, "a redução no espaçamento entre linhas e o aumento da densidade de plantio é uma realidade na cultura de milho, no Brasil,encontrando-se no mercado, inclusive, plataformas adaptáveis às colhedoras, que realizam a colheita em espaçamentos de até $0,45 \mathrm{~m}$ " (CRUZ et al., 2010). Entretanto um estante de plantas muito baixo pode ocorrer em função de inadequada regulagem das semeadoras-adubadoras de precisão (EMBRAPA,1996), velocidade de deslocamento, assim como, pelo mal funcionamento dos discos de corte da palha e a adequação do orifício do disco dosador conforme o tamanho da semente (SANTOS, 1999).

Avaliação da densidade de plantas de híbridos de milho semeado sem ambientes irrigados (um irrigado durante todo o ciclo e outro apenas de V15a R2)e de sequeiro (sob condições naturais de precipitação), verificou que utilizando altas densidades, desde que não ocorra nenhuma deficiência hídrica entre os estádios fenológicos de V15 e R2, é uma estratégia que possibilita otimizar a produção de grãos 
do milho semeado no final do invernonas regiões mais quentes do Sul do Brasil (DA SILVA SERPA et al., 2012).

\section{INFLUÊNCIA DA VELOCIDADE DE DESLOCAMENTO}

A identificação do limite de velocidade para a semeadura é importante para se ter um bom desempenho das máquinas semeadoras, além de ser necessário para manter a plantabilidade adequada, que inclui uma relação ideal de número de plantas/sementes distribuídas com semeadoras, a uniformidade de plantio, um espaçamento aceitável, porcentagem de espaçamento falho e duplo entre plantas (BERTELLI et al., 2016).

A velocidade de deslocamento ideal de uma semeadora é caracterizada pela qual possibilite que haja a abertura e fechamento adequado do sulco, sem grandes movimentações de solo, e as sementes sejam distribuídas em espaçamentos e profundidades adequadas (VIEIRA; REIS, 2001). Segundo Delafosse (1986), a velocidade de deslocamento é um dos fatores que mais influência no desempenho de semeadoras-adubadoras, pois vai afetar diretamente na distribuição longitudinal de sementes no sulco de semeadura.

É importante que haja uma distribuição de sementes uniforme, pois a desuniformidade no estabelecimento de plantas pode vir a atrapalhar as operações subsequentes durante o ciclo da cultura como pulverizações, tratos culturais e a colheita (PACHECO, 1996).

Segundo Mantovani (2002), a velocidade de semeadura de milho é variável de acordo com o sistema de distribuição, entretanto há uma faixa com limites recomendados, sendo de $4 \mathrm{~km} / \mathrm{h}$ a $6 \mathrm{~km} / \mathrm{h}$ para semeadoras de disco, e para as semeadoras a dedo ou a vácuo considera-se que até $10 \mathrm{~km} / \mathrm{h}$ se consegue obter uma semeadura satisfatória, entretanto os resultados podem variar em função das condições da topografia do terreno, umidade e textura do solo que possibilitaram ou não o implemento operar com esta velocidade, sendo que, elevando a velocidade de deslocamento de $5 \mathrm{~km} / \mathrm{h}$ para $10 \mathrm{~km} / \mathrm{h}$ pode ocorrer perdas em até $12 \%$.

Avaliando a emergência de plantas em três velocidades de deslocamento $(3,6$, 5,4 e 7,2 km h-1), Celik;Ozturk; Way (2007) verificaram que a velocidade de deslocamento da semeadora afetou significativamente o tempo médio de emergência e à medida que a velocidade aumentou, o tempo médio de emergência diminuiu e o 
menor tempo médio de emergência foi obtido na velocidade de deslocamento de 7,2 $\mathrm{km} \mathrm{h}^{-1}$.

Gonçalves et al. (2018), avaliando a influência da velocidade de deslocamento no desempenho de uma semeadora-adubadora de milho, com a regulagem para 70000 plantas.ha-1, utilizou três velocidades de deslocamento $(5,29$ / 8,29 / 13,43 km $\mathrm{h}^{-1}$ ) e verificou que a velocidade de $5,29 \mathrm{~km} \mathrm{~h}^{-1}$ teve número de sementes mais próximo da densidade esperada e conforme houve aumento da velocidade de deslocamento diminui o número de sementes depositadas por metro, espaçamento entre sementes e assim consequentemente a uniformidade de semeadura.

Bertelliet al. (2016), avaliando o desempenho da plantabilidade de semeadoras pneumáticas na implantação de soja no cerrado do Piauí, verificou que tanto para semeadora John Deere <sup> @ 2117, quanto John Deere <DB> ® DB74 a porcentagem de espaçamentos aceitáveis diminui conforme aumentou-se a velocidade de deslocamento, e em contrapartida o espaçamento falho elevou-se com o aumento da velocidade, reduzindo assim a uniformidade de plantio.

Estudo realizado por Mantovani et al. (1992), avaliaram a eficiência operacional de diferentes semeadoras-adubadoras de milho e verificaram que todas semeadoras avaliadas, submetidas a diferentes velocidades, demonstraram eficiência operacionalmente requerendo menor potência que a indicado pelos fabricantes.

Silva et al. (2000) verificaram o estabelecimento da cultura do milho em semeadura direta nas velocidades de 3,0; 6,0; 9,0 e 11,2 $\mathrm{km} \mathrm{h}^{-1}$ e detectaram que com o aumento da velocidade de deslocamento da semeadora-adubadora a quantidade de sementes/plantas na linha de semeadura reduziu. Resultados semelhantes também foram encontrados por Andersson (2001).

Trogelloet al. (2013), avaliando o desenvolvimento e produtividade da cultura do milho submetido a diferentes métodos de manejo de palhada, mecanismos sulcadores e velocidades de operação, verificou-se que os maiores valores de espaçamentos falhos e duplos ocorreram na velocidade de $7,0 \mathrm{~km} \mathrm{~h}^{-1}$, entretanto não observou diferenças significativas para a produtividade média da cultura de milho.

Analisando as variáveis de germinação do estande, distribuição longitudinal, plantas com espigas e outros componentes de rendimento em quatro condições de semeadura de milho e com a velocidade de variando de 3,0 a 9,0 km h-1, Garcia et 
al. (2006b) concluíram que elevando a velocidade de semeadura há aumento na percentagem de espaçamentos falhos e múltiplos e queda de espaçamentos aceitáveis, assim como queda do estante de plantas com espigas e consequentemente de produtividade. Corroborando com os resultados encontrados por Fey; Santos (2000), onde observaram que com o aumento da velocidade de deslocamento houve redução nos valores dos parâmetros avaliados, sendo estes, o estande, plantas com espigas, espaçamentos aceitáveis entre plantas e a produção de milho.

\section{CONCLUSÕES}

Pode se concluir que à medida que se aumenta a percentagem de espaçamentos falhos e múltiplos e queda de espaçamentos aceitáveis ao se elevar a velocidade de deslocamento da semeadora-adubadora, reduz drasticamente a uniformidade de plantio e consequentemente o rendimento de grãos.

\section{REFERÊNCIAS}

ANDERSSON, C. Avaliação técnica de semeadoras-adubadoras para plantio direto. Plantio Direto, Passo Fundo, n. 66, p. 28-32, 2001.

ARAÚJO, C. Grão em grão. Jornal Eletrônico da Embrapa Milho e Sorgo. Sete Lagoas-Mg, Ed.07. 2008.

ARGENTA, G.; SILVA, P. R. F. da.; SANGOI, L. Arranjo de plantas em milho: análise do estado-da-arte. Ciência rural. Santa Maria, v.. 31, n. 6, p. 1075-1084, 2001.

\section{ASSOCIAÇÃO BRASILEIRA DE NORMAS TÉCNICAS - ABNT. Projeto de norma}

04.015.06-004: semeadora de precisão - ensaio de laboratório - método de ensaio. Rio de Janeiro, 1994. 7 p.

BACCHI, M. D.; CALDARELLI, C. E.; SEREIA, V. J. Desempenho das exportações brasileiras de milho: uma análise de Constant-Market-Share para o período 2002 a 2012. Acta Scientiarum. Humanand Social Sciences, v. 39, n. 3, p. 271, 2017.

BERTELLI, G. A.; JADOSKI, S. O.; DA LUZ DOLATO, M.; RAMPIM, L.; MAGGI, M. F. Desempenho da plantabilidade de semeadoras pneumática na implantação da cultura da soja no cerrado piauiense-Brasil. Revista Brasileira de Tecnologia Aplicada nas Ciências Agrárias, v. 9, n. 1, 2016.

BONDESIO, S.; KLOPPERS, R.; OELLERMANN, H. Know the Maize Plant (SA). Pannar Seed, 2016. 
BONHOMME, R.; KINIRY J. R. Predicting maize phenology. In: HODGES, T. Predicting crop phenology. Crc Press, chapter 11, p. 115- 132, 1990.

BORÉM, A.; GALVÃO, J. C. C.; PIMENTEL, M. A. Milho: do plantio à colheita. Viçosa.Editora UFV. 351p, 2015.

CELIK, A.; OZTURK, I.; WAY, T. R. Effects of various planters on emergence and seed distribution uniformity of sunflower.AppliedEngineering in Agriculture, v. 23, n. 1, p. 57-61, 2007.

CRUZ, J. C.; PEREIRA, F. T. F.; PEREIRA FILHO, I. A.; DE OLIVEIRA, A. C.; MAGALHÃES, P. C. Resposta de cultivares de milho à variação em espaçamento $e$ densidade. RevistaBrasileira de Milho e Sorgo, v. 6, n. 01, 2010.

DA SILVA SERPA, M.; DA SILVA, P. R. F.; SANGOI, L.; VIEIRA, V. M.; MARCHESI, D. R. Densidade de plantas em híbridos de milho semeados no final do inverno em ambientes irrigados e de sequeiro. Pesquisa Agropecuária Brasileira, v. 47, n. 4, p. 541-549, 2012.

DARÓS, R. Cultura do milho. Manual de recomendações técnicas. 11p. 2008.

DELAFOSSE, R. M. Máquinas sembradoras de grano gruesso. Santiago: Oficina Regional de La FAO para America Latina y el Caribe, 1986. 48 p.

FANCELLI, A. L.; ALVES, L. R. A.; ALMEIDA, R. E. M. "A cadeia produtiva do milho". Piracicaba-SP. Esalq. VisãoAgrícola. n. 13, p.171, 2015.

FEY, E.; SANTOS, S.R.; FEY, A. Influência da velocidade de semeadura sobre a produtividade de milho (ZeamaysL.). In: CONGRESSO BRASILEIRO DE ENGENHARIA AGRÍCOLA, 29., 2000, Fortaleza. Anais... Fortaleza: Sociedade Brasileira de Engenharia Agrícola, 2000. 1 CDROM.

FOOD AND AGRICULTURE ORGANIZATION OF THE UNITED NATIONS FAO.CoarseGrains. [S. I.], 2018. Disponível em:

$<$ http://www.fao.org/agriculture/crops/agp-home/en/?no_cache=1>. Acesso em: 06 ago. 2018.

FORNSTROM, K. J.; MILLER, S. D. Comparison of sugarbeet planters and planting depth with two sugarbeetvarieties.J. Am. Soc. Sugarbeet Technol, n.26, p. 10-16, 1989.

FORSTHOFER, E. L.; SILVA, P. R. F. D.; STRIEDER, M. L.; MINETTO, T. J.; RAMBO, L.;ARGENTA, G.; SILVA, A. A. D. Desempenho agronômico e econômico do milho em diferentes níveis de manejo e épocas de semeadura. Pesquisa

Agropecuária Brasileira: 1977. Brasília. Vol. 41, n. 3 (mar. 2006), p. 399-407, 2006. 
GALINAT, W. C. The origin of maize. Annual review of genetics, v. 5, n. 1, p. 447478, 1971.

GARCIA, J. C.; MATTOSO, M. J.; DUARTE, J. O.; CRUZ, J. C. Aspectos Econômicos da Produção e Utilização do Milho. Sete Lagoas, MG: EMBRAPA CNPMS. Dezembro, 2006a. 12 p. (Circular técnica 74).

GARCIA, L. C.; JASPER, R.; JASPER, M.; FORNARI, A. J.; BLUM, J. Influência da velocidade de deslocamento na semeadura do milho. Engenharia Agrícola, p. 520$527,2006 \mathrm{~b}$.

GONÇALVES, B. C.; OLIVEIRA, C. M.; DOS ANJOS, D. C. A.; LIMA, A. N. R.; da Cunha SIQUEIRA, W.; SANTOS, A. F. S.; ABRAHÃO, S. A. Desempenho de uma semeadora-adubadora na uniformidade do plantio de milho em diferentes velocidades. $1^{\circ}$ simpósio mato-grossense de mecanização agrícola e agricultura de precisão - simapufmt, Sinop, p.3, 2018.

HATFIELD, J. L.; BOOTE, K. J.; KIMBALL, B. A.; ZISKA, L. H.; IZAURRALDE, R. C.; ORT, D.; WOLFE, D. Climate Impacts on Agriculture: Implications for Crop Production. AgronomyJournal, v.103, n. 2, p. 351, 2011.

JORNAL AGROCERES. São Paulo: AGROCERES, n. 219, janeiro 1994.

KACHMAN, S. D.; SMITH, J. A. Alternative measures of accuracy in plant spacing for planters using single seed metering. Transactions of the ASAE 38(2): 379-387, 1995.

LAURIANO, S. M. Plantabilidade: importância da qualidade de plantio. Inspeção periódicas de semeadoras FCA - UNESP, Botucatu -SP, p. 57, 2015.

MAGALHÃES, P. C.; DURÃES, F. O. M.; CARNEIRO, N. P.; PAIVA, E. Fisiologia do Milho. Sete Lagoas, MG: EMBRAPA - CNPMS. Dezembro, 2002. 23 p. (Circular técnica 22) ISSN 1679-1150.

MANTOVANI, E. C. Cultivo de milho: plantadoras. Embrapa Milho e SorgoComunicado Técnico (INFOTECA-E), 2002

MANTOVANI, E. C.; BERTAUX, S.; ROCHA, F. E. C. Avaliação da eficiência operacional de diferentes semeadoras-adubadoras de milho. Pesquisa

Agropecuária Brasileira, Brasília, v. 27, n. 12, p. 1579-86, 1992.

MANTOVANI, E. C.; CRUZ, J. C.; DE OLIVEIRA, A. C. avaliação em campo de uma semeadora-adubadora para plantio de milho de alta densidade. Revista Brasileira de Milho e Sorgo, v. 14, n. 1, p. 38-48, 2015.

MANTOVANI, E. C.I.; CRUZ, J. C.; OLIVEIRA, A. C. de. Avaliação em campo de uma semeadora-adubadora para plantio de Milho de alta densidade. XLII 
Congresso Brasileiro de Engenharia Agrícola - CONBEA 2013, 04 a 08 de Agosto de 2013 - Fortaleza - CE. Brasil. Disponível em:

http://rbms.cnpms.embrapa.br/index.php/ojs/article/download/526/pdf_116. Acesso 04 jul de 2019.

MARONI, J. R.; FERNANDEZ ASENJO, A.; GARGICEVICH, A.; REPETTO, L.; GONZÁLEZ, C. Velocidad de emergenciadelmaíz: prestaciones de diferentes órganos para elcontactadosemilla-suelo durante lasiembra. In: BARBOSA, O.A. (ed.). Avances em ingeniería agrícola 2003-2005. San Luis: CADIR 2005, 2005. p. 9-14.

MÁRQUEZ, L. Maquinaria agrícola. Madrid: B\&H, 2004. 700 p.

NATIONAL CORN GROWERS ASSOCIATION - NCGA.The many uses of corn. Disponível em: < http://worldofcorn.com/pdf/NCGA_CornUsesPoster.pdf/http://www.ncga.com/upload/f iles/documents/pdf/cornusesposter.pdf>. Acessoem: 04 jul. 2019.

OTTMAN, M.J.; WELCH, L.F. Planting patterns and radiationinterception, plant nutrient concentration, and yield in corn.AgronomyJournal, Madison, v.81, n.2, p.167-174, 1989.

PIPERNO, D. R.; FLANNERY, K. V. The earliest archaeological maize (Zea mays L.) from highland Mexico: new accelerator mass spectrometry dates and their implications. Proceedings of the National Academy of Sciences, v. 98, n. 4, p. 2101-2103, 2001.

RUSSEL, W.A. Genetic improvement of maize yields. Advancesin Agronomy, Cambridge, v.46, n.1, p.245-298, 1991.

SANGOI, L. Understanding plant density effects on maize growth and development:na important issue to maximize grain yield. Ciência Rural, Santa Maria, v. 31 , n. 1 , p. $159-168,2000$.

SANTOS, S. Distribuição de sementes de soja (Glycinemax (L.) Merrill), sob diferentes discos perfurados e velocidades de avanço. In: CONGRESSO BRASILEIRO DE SOJA, 1999. Londrina. Anais... Londrina: Embrapa, 1999. p.343.

SCHMIDT, A. V. C. J. L.; GAUSMANN, E.; MELO, I. J. B. Semeadora adubadora para plantio direto.Emater, Porto Alegre, 1999. p. 56.

SILVA, J. G.; KLUTHCOUSKI, J.; SILVEIRA, P. M. Desempenho de uma semeadora-adubadora no estabelecimento e na produção da cultura do milho sob plantio direto. Scientia Agrícola, Piracicaba, 57, n. 1, p. 7-12, 2000.

SILVA, P. R. A. Semeadora-adubadora: mecanismos de corte de palha e cargas verticais aplicadas. 2007. xii, 93 f. Tese (doutorado) - Universidade Estadual 
Paulista, Faculdade de Ciências Agronômicas, 2007. Disponível em: <http://hdl.handle.net/11449/101705>.

SILVA, R. P. Efeito de rodas compactadoras submetidas a cargas verticais em profundidades de semeadura nas características agronômicas do Milho (Zeamays L.). 2002. 101 f. Tese (Doutorado em Produção Vegetal) Faculdade de Ciências Agrárias e Veterinárias, Universidade Estadual Paulista, Jaboticabal, 2002.

TEIXEIRA, M. C. C.; BEMYGDIO, B. M.; RODRIGUES, O. Efeito da densidade de plantas e espaçamento entre linhas no desempenho de cultivares de milho da Embrapa. Passo Fundo: Embrapa Trigo, 2006. 14 p. html (Embrapa Trigo. Boletim de Pesquisa e Desenvolvimento Online, 34). Disponível em:<http://www.cnpt.embrapa.br/biblio/bp/p_bp34.htm> Acesso 04jul. 2019.

TOLEDO, A. Semeadora, semeadeira ou plantadeira? Entenda as diferenças entre os termos técnicos e as máquinas. Mecaniza - Inovação e Pesquisa em Mecanização Agrícola, 2015. Disponível em: <https://mecaniza.org/semeadorasemeadeira-plantadeira-diferencas> Acesso 04 jul. 2019.

TROGELLO, E.; MODOLO, A. J.; SCARSI, M.; DALLACORT, R. Manejos de cobertura, mecanismos sulcadores e velocidades de operação sobre a semeadura direta da cultura do milho. Bragantia, v. 72, n. 1, 2013.

VIEIRA, L. B.; REIS, E. F. Máquinas para o plantio direto. Informe agropecuário, Belo Horizonte, v. 22, n. 208, p. 43-48, 2001.

VON PINHO, R. G.; VASCONCELOS, R. D.; BORGES, I. D.; RESENDE, A. D. Produtividade e qualidade da silagem de milho e sorgo em função da época de semeadura. Bragantia, v. 66, n. 2, p. 235-245, 2007.

WAND, S. J. E.; MIDGLEY, G. F.; JONES, M. H.; CURTIS, P. S. Responses of wild C4 and $\mathrm{C} 3$ grasses (Poaceae) species to elevated atmospheric $\mathrm{CO}_{2}$ concentration: $\mathrm{A}$ meta-analytic test of current theories and perceptions. Glob. Change Biol. V.5, p. 723-741, 1999.

YABUNO, T. Cytotaxonomic studies on the two cultivated species and the wild relatives in the genus Echinochloa. Cytologia, v. 27, n. 3, p. 296-305, 1962. 